\title{
Cumulus cells and their extracellular matrix affect the quality of the spermatozoa penetrating the cumulus mass
}

\author{
Shun-Jia Hong, Ph.D., ${ }^{\mathrm{a}}$ Philip Chi-Ngong Chiu, Ph.D., ${ }^{\mathrm{b}}$ Kai-Fai Lee, Ph.D., ${ }^{\mathrm{b}}$ Jenny Yin-Mei Tse, \\ Ph.D., ${ }^{\mathrm{c}}$ Pak-Chung Ho, M.D., ${ }^{\mathrm{b}}$ and William Shu-Biu Yeung, Ph.D. ${ }^{\mathrm{b}}$ \\ ${ }^{\mathrm{a}}$ Department of Obstetrics and Gynecology, Second Affiliated Hospital, Sun Yat-sen University, Guangdong; ${ }^{\mathrm{b}}$ Department of \\ Obstetrics and Gynecology, University of Hong Kong, Queen Mary Hospital, Pokfulam, Hong Kong; and ${ }^{\mathrm{c}}$ Innovation and \\ Technology Commission, Wanchai, Hong Kong, China
}

\begin{abstract}
Objective: To investigate the role of the cumulus cells and the cumulus matrix in affecting the penetrability, morphology, acrosome reaction, and motility of human spermatozoa penetrating the cumulus oophorus.

Design: Controlled experimental laboratory study.

Setting: University gynecology unit.

Patient(s): Women undergoing assisted reproduction treatment and men visiting the subfertility clinics.

Intervention(s): Human spermatozoa were allowed to penetrate through the cumulus oophorus and cell-depleted cumulus matrix in a capillary, and were treated with cumulus cell extract or hyaluronic acid.

Main Outcome Measure(s): The morphology, acrosomal status, and motility of human spermatozoa were determined.

Result(s): Fewer spermatozoa could penetrate the fresh cell-depleted matrix compared with intact cumulus oophorus. Spermatozoa that penetrated through the cumulus oophorus had higher percentages of normal morphology and acrosome reaction and had specific motility pattern. These effects were lost or reduced in the cell-depleted matrix that had been stored overnight. Hyaluronic acid, a main component of the cumulus matrix at concentration found in the cumulus oophorus, modulated sperm motility but did not affect spontaneous acrosome reaction. Cumulus cell extract did not affect sperm motility, but induced acrosome reaction.

Conclusion(s): Both the cumulus matrix and the cumulus cells contribute to the effect of cumulus oophorus on spermatozoa penetrating through it. (Fertil Steril ${ }^{\circledR} 2008 ; \boldsymbol{\square}: \mathbf{\square}$. ( $९ 2008$ by American Society for Reproductive Medicine.)
\end{abstract}

Key Words: Cumulus oophorus, human spermatozoa, morphology, motility, acrosome reaction

At ovulation, an oocyte and its associated cumulus oophorus containing follicular fluid are transported to the oviduct. To fertilize the oocyte, spermatozoa have to pass through the cumulus oophorus encountering the cumulus cells and their extracellular matrix during the passage (1-3). The cumulus matrix contains filaments and granules that appear to be associated with the plasma membrane of the cumulus cells (4). Human spermatozoa can penetrate the cumulus oophorus within $1 \mathrm{~h}$ in vitro (5), and capacitated hamster spermatozoa take 3-20 min to do so $(6,7)$.

Failure of cumulus oophorus formation leads to fertilization problems (8-10). Earlier studies have reported that the cumulus cells affected sperm functions in vitro (11-18). One report showed that coculture of human spermatozoa with cumulus cells significantly increased the fusion of spermatozoa with zona-free hamster oocyte (12). We had also demonstrated

Received May 19, 2008; revised and accepted July 11, 2008.

S.-J. H. has nothing to disclose. P. C.-C. has nothing to disclose. K.-F. L. has nothing to disclose. J.Y.-M. T. has nothing to disclose. P.-C. H. has nothing to disclose. W.S.-B. Y. has nothing to disclose.

Supported by grants from the Research Grant Council, Hong Kong (HKU 7408/03M).

Reprint requests: Dr. W. S.-B. Yeung, Department of Obstetrics and Gynaecology, University of Hong Kong, Queen Mary Hospital, Hong Kong, China (FAX: 852-28550947; E-mail: wsbyeung@hkucc.hku.hk). that the cumulus cells reduced the spermatozoa-zona binding inhibitory activity of human follicular fluid (19) and enhanced the zona-binding capacity of spermatozoa passing through the cumulus oophorus (18). However, there is a conflicting report describing detrimental effects on sperm motility after coculture of spermatozoa with the cumulus cells (15).

The action of cumulus cells on sperm function may be mediated via the secretory products of the cells $(11,13,18,20$, 21 ). Thus, spent medium from cumulus cell culture induced acrosome reaction (11) and stimulated sperm motility (13). However, the physiologic significance of these observations remain to be demonstrated, because the conditioned medium used in these studies was collected after prolonged cumulus cell culture, which might have affected the normal physiology of the cells. Indeed, the flattened morphology of cultured cumulus cells is very different from the spherical cumulus cells found in the cumulus oophorus (17). Moreover, the concentration of the secretory products in the conditioned medium is likely to be much lower than that in the cumulus matrix.

The components of the extracellular matrix of cumulus oophorus affect various sperm functions. Hyaluronic acid is a major component of the cumulus matrix (22-25) and is synthesized by the cumulus cells after LH surge (26). Hyaluronic 
acid affects human sperm motility (20) and acrosome reaction (27) in vitro. These latter studies used different hyaluronic acid concentrations up to $100 \mu \mathrm{g} / \mathrm{mL}$, which is much lower than the concentration $(0.5-1 \mathrm{mg} / \mathrm{mL})$ in the cumulus matrix $(22,26)$. The effect of hyaluronic acid at a concentration similar to that in the cumulus mass on sperm function remains unclear.

Compared with spermatozoa incubated in medium alone, those that had passed through the cumulus mass had a higher percentage of spermatozoa with normal morphology and reacted acrosome, a specific motility pattern and higher zona-binding capacity $(17,18)$. We hypothesized that both the extracellular matrix and the cumulus cells contribute to these effects on spermatozoa. To test this hypothesis, three sets of experiments were carried out to study the treatment effects of cumulus cells and their extracellular matrix on sperm functions. These treatments included the use of: 1) viable cumulus cells; 2) products of cumulus cells; and 3) hyaluronic acid at concentrations similar to that in the cumulus mass.

\section{MATERIALS AND METHODS}

\section{Semen Samples}

The Ethics Committee, University of Hong Kong, approved the research protocol. All semen samples were collected from men visiting the subfertility clinic, Queen Mary Hospital. Only semen samples with normal semen parameters according to World Health Organization criteria (28) were used. After liquefaction and routine semen analysis, the semen was processed with the swim-up method (28). The percentage of motile spermatozoa collected was $>95 \%$. The spermatozoa were capacitated in 3\% bovine serum albumin (BSA) in Earle's balanced salt solution for $3 \mathrm{~h}$. The sperm concentration was determined and adjusted to a concentration of $10 \times 10^{6}$ motile spermatozoa $/ \mathrm{mL}$ in Earle's balanced salt solution supplemented with $0.3 \%$ BSA (EBSS/BSA).

\section{Collection of Cumulus Oophorus}

Cumulus-oocyte complexes were obtained from women who came for treatment with intracytoplasmic sperm injection owing to male infertility. Human menopausal gonadotropin (Serono, Geneva, Switzerland) was used for ovarian stimulation after down-regulation with buserelin (29). After oocyte retrieval, cumulus oophorus were dissected mechanically from the cumulus-oocyte complex using a syringe needle and a glass pipette. Cumulus oophorus from each patient was pooled in EBSS/BSA before experimentation.

To prepare the cell-depleted matrix, about two-thirds of the cumulus masses obtained from each patient were frozen at $-70^{\circ} \mathrm{C}$ and then thawed at $4^{\circ} \mathrm{C}(30)$ three times. The fresh cumulus masses and one-half of the frozen-thawed cumulus mass were used for experimentation on the day of collection (fresh matrix). The other half of the frozen-thawed cumulus masses were incubated overnight at $4{ }^{\circ} \mathrm{C}$ (overnight matrix) for experimentation the next day. The overnight matrix was pre-equilibrated at $37^{\circ} \mathrm{C}$ in $5 \% \mathrm{CO}_{2}$ in air before use.
To prepare the cumulus cell extract, cumulus cells were collected after hyaluronidase dispersion and washing by centrifugation with EBSS/BSA. The cells were resuspended in an appropriate volume of phosphate-buffered salin supplemented with $0.25 \mathrm{mmol} / \mathrm{L}$ phenylmethylsulfonyl fluoride to give a viable cell concentration of $8 \times 10^{6}$ cells $/ \mathrm{mL}$. Our unpublished data show that phenylmethylsulfonyl fluoride at the concentration used did not affect sperm viability and motility, as determined by computer-assisted sperm analysis, consistent with earlier observations (31). The cell suspensions underwent freeze-thaw cycle described above three times. The cell extract was obtained by centrifugation at $10,000 \mathrm{~g}$ for $10 \mathrm{~min}$ at $4{ }^{\circ} \mathrm{C}$ in an Eppendorf centrifuge (5417R; Eppendorf, Hamburg, Germany) to remove cell debris, and extracts from different patients were stored individually at $-70^{\circ} \mathrm{C}$ and used within 2 weeks.

\section{In Vitro Cumulus Oophorus Model}

A capillary-cumulus model was used (17). In brief, a sterile glass capillary (Microcaps; Drummund, Broomall, PA) with an inner diameter of $0.7 \mathrm{~mm}$ was attached to a $1 \mathrm{~mL}$ disposal syringe (Terumo, Tokyo, Japan) and prewarmed in a mobile Hoffman IVF Chamber (Air-shields; Vickers, Hatboro, PA) at $37^{\circ} \mathrm{C}$ with humidified air containing $5 \% \mathrm{CO}_{2}$. The capillary was successively filled with EBSS/BSA to a length of $3 \mathrm{~cm}$ (medium column), and 1-2 pieces of cumulus oophorus/cumulus matrix to form a cumulus column of length $2 \mathrm{~cm}$. The end of the capillary with the cumulus column was dipped into a 100$\mu \mathrm{L}$ droplet of sperm suspension containing $10 \times 10^{6}$ motile spermatozoa/mL overlaid with mineral oil. Another capillary containing only EBSS/BSA serves as control. The capillaries were incubated for $1 \mathrm{~h}$, when the capillary was cut with a diamond pen at the interface between the cumulus column and the medium column. The medium column containing spermatozoa that had passed through the cumulus oophorus (penetrated spermatozoa) were expelled into a microcentrifuge tube. The control capillary was cut at a level that was at the same distance from the end of the experimental capillary. Spermatozoa that had swum above the cutting level of the control capillary were collected as the control spermatozoa.

\section{Determination of Sperm Morphology}

Six microliters of the sperm suspension was smeared on a glass slide and air dried. The slides were fixed in methanol and stained with the Diff-Quik procedure. One observer, who was blinded to the treatment of the sperm samples, performed the morphology assessment. The morphology of 200 spermatozoa per sample were assessed at $\times 1,000$ magnification under oil immersion with a microscope (Zeiss, Oberkochen, Germany) using strict criteria (32).

\section{Determination of Acrosomal Status and Motility of Spermatozoa}

Fluorescein isothiocyanate-labeled peanut (Pisum sativum) agglutinin (FITC-PSA; Sigma) was used to evaluate the acrosomal status of the spermatozoa as previously described (33, 34). Two slides were prepared for each sample. The 
fluorescence patterns of 300 spermatozoa in randomly selected fields of each slide were determined under a microscope (Zeiss) with $\times 1,000$ magnification. The acrosomal status of spermatozoa was classified according to the lectin staining as: 1) intact acrosome: complete staining of acrosome; 2) reacting acrosome: partial or patchy staining of acrosome; or 3) reacted acrosome: complete staining of the equatorial segment only or no staining of the sperm head. The proportions of the three patterns were expressed as percentages of the total number of spermatozoa counted. Two observers were involved in scoring the acrosome reaction. In optimization of the experiment, there was no significant difference in the scoring of eight samples between the two observers (Pearson correlation coefficient 0.86).

Hobson Sperm Tracker System (Hobson Tracking Systems, Sheffield, U.K.) was used to determine the motility of spermatozoa by a single observer. The set-up parameters of the system and the procedures were as described previously (35). Five hundred spermatozoa per specimen in randomly selected fields were evaluated to determine: 1) curvilinear velocity (VCL, $\mu \mathrm{m} / \mathrm{s}$ ); 2) mean straight-line velocity (VSL, $\mu \mathrm{m} / \mathrm{s}$ ); 3 ) average-path velocity (VAP, $\mu \mathrm{m} / \mathrm{s}$ ); 4) mean linearity (LIN; VSL/VCL); 5) amplitude of lateral head displacement (ALH, $\mu \mathrm{m})$; and 6) head beat cross-frequency (BCF, Hz). All samples were processed in triplicate.

\section{Effect of Cell-Depleted Cumulus Mass}

The effects of fresh cumulus mass, fresh matrix of a patient, and overnight matrix prepared the day before from another patient on sperm functions were compared using the capillary model described above. In each experiment, spermatozoa from the same ejaculate were used to penetrate the three groups of cumulus masses/matrix. The functions of the penetrated spermatozoa from different groups were compared. Spermatozoa that had swum up a capillary filled with medium only were used as control.

\section{Effect of Cumulus Cell Extract on Sperm Functions}

Processed spermatozoa were capacitated for $3 \mathrm{~h}$. Thirty-five microliters of the capacitated spermatozoa at concentration of $23 \times 10^{6}$ spermatozoa $/ \mathrm{mL}$ were then incubated with 5 $\mu \mathrm{L}$ of the cell extract, which was equivalent to extract from $4 \times 10^{4}$ cumulus cells. After $1 \mathrm{~h}$, the spermatozoa were washed with fresh EBSS/BSA twice, and the sperm functions were assayed. Sperm without treatment was used as control.

\section{Effect of Hyaluronic Acid on Sperm Functions}

Spermatozoa were capacitated in EBSS containing 3\% BSA for $3 \mathrm{~h}$. They were treated with hyaluronic acid (Sigma, St. Louis, MO) at a final concentration of $1.0 \mathrm{mg} / \mathrm{mL}$ for $1 \mathrm{~h}$. The functions of the treated spermatozoa were assayed. Spermatozoa without treatment served as control. The treated spermatozoa were then washed with fresh medium, and their acrosomal status reaction was evaluated with the FITC-PSA staining technique.

\section{Data Analysis}

Sigmastat statistical software (Jandel Scientific, San Rafael, CA) was used to analyze the data. Results for the concentration of penetrated spermatozoa are expressed as mean \pm SD and analyzed with one-way analysis of variance (ANOVA). Percentages were transformed to arcsine values using the Freeman and Tukey transformation and were analyzed with Kruskal-Wallis one-way ANOVA on ranks. If the software detected that the data were normally distributed, one-way ANOVA was used followed by multiple comparisons using the Student-Newman-Keuls test.

\section{RESULTS \\ Effect of Cumulus Matrix on Sperm Function}

Dye exclusion test showed that there was no viable cell in the cumulus matrix after repeated freeze-thaw cycles of the cumulus oophorus. The cell-depleted matrix retained its intact elastic texture after the freeze-thaw cycle and after overnight storage. The concentration of penetrated spermatozoa in the medium column of the capillaries filled with fresh matrix $\left(0.17 \pm 0.02 \times 10^{6}\right.$ spermatozoa $\left./ \mathrm{mL}\right)$ and overnight matrix $\left(0.19 \pm 0.03 \times 10^{6}\right.$ spermatozoa/mL $)$ was significantly lower $(\mathrm{n}=10 ; P<.05)$ than that in capillaries containing fresh cumulus mass $\left(0.24 \pm 0.03 \times 10^{6}\right.$ spermatozoa/mL $)$. The percentage of spermatozoa with normal morphology was significantly $(P<.05)$ higher in the capillaries with intact cumulus oophorus (median $40 \%$, range $32 \%-46 \%$ ) and with fresh matrix (median $41 \%$, range 30\%-48\%) compared with those containing medium only (median 20\%, range 13\%-31\%) and overnight matrix (median $21 \%$, range $16 \%-32 \%$ ).

\section{FIGURE 1}

The acrosomal status of spermatozoa after penetrating various cumulus columns $(n=10)$ determined by fluorescein isothiocyanate-labeled peanut agglutinin staining. Values are median with interquartile range. ${ }^{\mathrm{a}, \mathrm{b}} \mathrm{P}<.05$ between values with different superscripts.

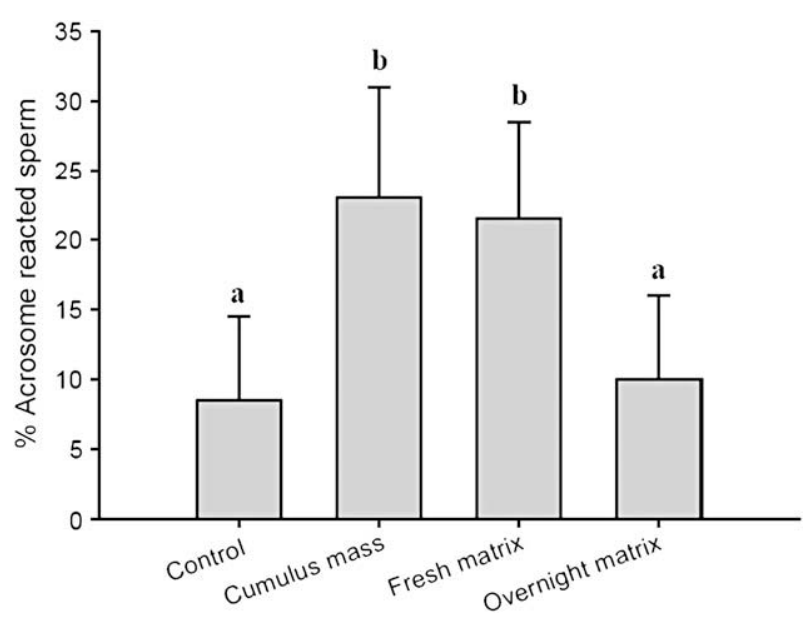

Hong. Cumulus oophorus and sperm penetration. Fertil Steril 2008. 


\section{TABLE 1}

Motility of spermatozoa after penetrating various cumulus columns $(n=10)$.

\begin{tabular}{|ccccc|}
\hline & Control & Cumulus mass & Fresh matrix & Overnight matrix \\
\hline VCL $(\mu \mathrm{m} / \mathrm{s})$ & $138(126-174)$ & $140(124-170)$ & $141(123-168)$ & $139(125-167)$ \\
VAP $(\mu \mathrm{m} / \mathrm{s})$ & $57(44-72)^{\mathrm{a}}$ & $75(58-92)^{\mathrm{b}}$ & $84.5(60-89)^{\mathrm{b}}$ & $59.5(46-70)^{\mathrm{a}}$ \\
VSL $(\mu \mathrm{m} / \mathrm{s})$ & $47(27-51)^{\mathrm{a}}$ & $58(44-75)^{\mathrm{b}}$ & $66(44-71)^{\mathrm{b}}$ & $42(31-48)^{\mathrm{a}}$ \\
BCF $(\mathrm{Hz})$ & $12.5(9-15)^{\mathrm{a}}$ & $15.5(11-1)^{\mathrm{b}}$ & $17(11-20)^{\mathrm{b}}$ & $12(9-15)^{\mathrm{a}}$ \\
LIN $(\%)$ & $29(16-34)^{\mathrm{a}}$ & $40(32-51)^{\mathrm{b}}$ & $41(32-49)^{\mathrm{b}}$ & $28(19-38)^{\mathrm{a}}$ \\
ALH $(\mu \mathrm{m})$ & $10(8-16)^{\mathrm{a}}$ & $8(5-10)^{\mathrm{b}}$ & $6.5(5-9)^{\mathrm{b}}$ & $10(8-14)^{\mathrm{a}}$ \\
\hline
\end{tabular}

Note: Values are median with range in parentheses. ALH = amplitude of lateral head displacement; BCF $=$ head beat cross-frequency; LIN = linearity (VSL/VCL); VAP = average-path velocity; VCL = curvilinear velocity; VSL = straightline velocity.

${ }^{a, b} P<.05$ between values with different superscripts within the same row.

Hong. Cumulus oophorus and sperm penetration. Fertil Steril 2008

In spite of the reduced penetrability to spermatozoa, fresh matrix had similar effects on sperm functions compared with intact cumulus oophorus. In contrast, most of the effects on sperm function were lost or reduced after overnight storage of the matrix (Fig. 1 and Table 1). Compared with those in the control capillary, spermatozoa traversed through either the cumulus mass or fresh matrix had a higher incidence of acrosome reaction (Fig. 1). Spermatozoa collected from the capillaries with cumulus mass and fresh matrix also exhibited higher VAP, VSL, BCF, and LIN, but lower ALH compared with the control spermatozoa (Table 1). Spermatozoa penetrated through the overnight matrix had all the sperm functional parameters studied similar to that of the control spermatozoa (Fig. 1).

\section{Effect of Cumulus Cell Extract on Sperm Motility}

To confirm the effect of cumulus cells on sperm function, extract of the cells was used instead of cumulus cell conditioned medium or coculture to avoid possible functional changes of cells after culture. The effects of cumulus cell extract on sperm motility are shown in Table 2 . The velocities of the spermatozoa decreased with incubation. There was no difference in all the sperm motility parameters measured between spermatozoa treated with the cumulus cell extract and the control at the same time point.

\section{Effect of Cumulus Cell Extract on Acrosome Reaction}

In medium alone, the percentage of spermatozoa with intact acrosome decreased and that of those with reacted acrosome increased with incubation (Table 3). Capacitated spermatozoa treated with cumulus cell extract for $1 \mathrm{~h}$ had significantly higher percentage of acrosome-reacted spermatozoa and lower percentage of spermatozoa with intact acrosome when compared with those incubated in medium alone at the same time point.

\section{Effect of Hyaluronic Acid on Sperm Functions}

Spermatozoa were capacitated in vitro for $3 \mathrm{~h}$ before hyaluronic acid treatment for $1 \mathrm{~h}$. The effects of the treatment on sperm motility are shown in Table 4 . Treatment with 1.0 $\mathrm{mg} / \mathrm{mL}$ of hyaluronic acid significantly increased VAP and VSL, but not VCL, compared with control at the same time point. Therefore, LIN (VSL/VCL) of hyaluronic acid-treated spermatozoa increased significantly. There were no differences in BCF and ALH between the hyaluronic acid-treated and control spermatozoa.

The effects of hyaluronic acid on spontaneous acrosome reaction are shown in Figure 2. Hyaluronic acid treatment did not affect spontaneous acrosome reaction (Fig. 2); the

\section{TABLE 2}

Effect of cumulus cell extract on sperm motility $(n=10)$.

\begin{tabular}{|llcccccc|}
\hline Capacitation & \multicolumn{1}{c}{ Group } & VCL & VAP & VSL & BCF & LIN & ALH \\
\hline $0 \mathrm{~h}$ & Control & $155(135-163)^{\mathrm{a}}$ & $85(72-91)^{\mathrm{a}}$ & $65(56-80)^{\mathrm{a}}$ & $15(13-22)$ & $42(31-48)$ & $8(7-13)$ \\
$\mathrm{3} \mathrm{h}$ & Medium alone & $145(122-153)^{\mathrm{b}}$ & $76(62-87)^{\mathrm{b}}$ & $61(45-70)^{\mathrm{b}}$ & $15(11-18)$ & $40(34-46)$ & $7(6-11)$ \\
& Cell extract & $146(124-156)^{\mathrm{b}}$ & $78(65-86)^{\mathrm{b}}$ & $62(49-68)^{\mathrm{b}}$ & $15(12-19)$ & $42(30-47)$ & $7(5-12)$ \\
\hline
\end{tabular}

Note: Values are median with range in parentheses. Abbreviations as in Table 1.

${ }^{a, b} P<.01$ between values with different superscripts within the same column compared with that at $0 \mathrm{~h}$. There was no significant difference $(P>.05)$ between the control and test groups at the same time point by paired $t$ test. 


\section{TABLE 3}

Effect of cumulus cell extract on acrosomal status.

\begin{tabular}{llrrr|} 
Capacitation & \multicolumn{1}{c}{ Group } & Intact & Reacting & Reacted \\
\hline $\mathrm{O} \mathrm{h}$ & Control & $92.5(88-94)^{\mathrm{a}}$ & $3(2-4)$ & $6(2-9)^{\mathrm{a}}$ \\
$\mathrm{3} \mathrm{h}$ & Medium alone & $82(78-88)^{\mathrm{b}}$ & $4(2-6)$ & $12.5(9-15)^{\mathrm{b}}$ \\
& Cell extract & $76(70-81)^{\mathrm{c}}$ & $3(2-5)$ & $20(15-24)^{\mathrm{c}}$ \\
\hline
\end{tabular}

Note: Values are median with range in parentheses.

${ }^{\mathrm{a}, \mathrm{b}} \mathrm{P}<.01$ between values with different superscripts within the same column compared with the control at $0 \mathrm{~h}$.

${ }^{\mathrm{c}} P<.05$ between values with superscripts within the same column compared with the control at the same time point.

Hong. Cumulus oophorus and sperm penetration. Fertil Steril 2008.

percentage of acrosome-reacted spermatozoa was similar between the hyaluronic acid-treated group and the mediumalone control group.

\section{DISCUSSION}

Spermatozoa have to traverse the cumulus oophorus to reach the oocyte (36). Therefore, the cumulus oophorus is at an ideal position to modulate the fertilizing ability of spermatozoa passing through it. Indeed, the cumulus oophorus is known to affect human sperm functions (11-18) and failure of its formation affects fertilization (8-10). The present study was designed to differentiate the roles of extracellular matrix and cumulus cells in affecting the functions of spermatozoa traversing the cumulus mass. It is the first report on the effect of intact cumulus matrix without viable cumulus cells on the functions of human spermatozoa. The capillary-cumulus model ensured that only the sperm population that had penetrated through the matrix was studied. Cumulus matrix is a complex structure with numerous interacting/cross-linking molecules (37). Therefore, its action on sperm function could be different from previous studies reporting the action of purified forms of some of components of the matrix on spermatozoa. Our data showed that fewer spermatozoa could penetrate the cell-depleted matrix than the cumulus oophorus, suggesting that viable cumulus cells affect the penetrability of spermatozoa through the cumulus mass. The underlying mechanism for this effect of viable cumulus cells is obscure and can only be speculated upon.

The cumulus cells may provide an optimal microenvironment beneficial to both the oocyte and the fertilizing sperma- tozoa $(36,38)$. Cumulus cells may affect sperm function by modifying the concentration of nutrients in the cumulus matrix. Lactate is the preferred energy substrate in spermatozoa (39). A sperm-specific lactate dehydrogenase isozyme C4 is present in spermatozoa for energy metabolism $(39,40)$. Lactate dehydrogenase has been localized to the postacrosomal region of human spermatozoa (41) and its deficiency in semen is associated with reduction in sperm motility and concentration (42) and with male infertility (43).

In the present study, the incubation medium contained glucose but no lactate. Human cumulus cells actively metabolize glucose to lactate in vitro (44). Therefore, the concentration of glucose was likely to be lower and that of lactate higher in the fresh cumulus mass than in the surrounding medium. The glucose and lactate levels in the matrix would gradually change after destruction of the cumulus cells by freeze-thaw cycles in this study, and they became identical to that of the incubation medium after overnight incubation. Compared with the overnight matrix, the higher lactate concentration in the fresh cumulus mass might provide a more efficient energy substrate for sperm motion, leading to more spermatozoa penetrating through the fresh cumulus mass than through the overnight matrix. It is interesting to note that the concentration of lactate increases while that of glucose decreases in human oviductal fluid during midcycle compared with follicular and luteal phases (44). Mouse oviductal fluid from oviduct with cumulus-oocyte complexes also contains less glucose and more pyruvate than that from oviduct without the complex (45).

Human spermatozoa generate reactive oxygen species (ROS) (46). Low concentration of ROS is important for

\begin{tabular}{|c|c|c|c|c|c|c|}
\hline \multicolumn{7}{|c|}{ Effects of hyaluronic acid on sperm motility $(n=10)$. } \\
\hline Treatment & VCL $(\mu \mathrm{m} / \mathrm{s})$ & VAP $(\mu \mathrm{m} / \mathrm{s})$ & VSL $(\mu \mathrm{m} / \mathrm{s})$ & BCF (Hz) & LIN (\%) & ALH $(\mu \mathrm{m})$ \\
\hline Medium alone & 146 (128-160) & $72.5(54-86)$ & 55.5 (36-70) & $15(10-18)$ & $40.5(30-48)$ & $7(5-9)$ \\
\hline $1.0 \mathrm{mg} / \mathrm{mL}$ & $150(133-164)$ & $79(73-91)^{a}$ & $64.5(55-74)^{a}$ & $16(12-18)$ & $46(37-52)^{a}$ & $7(5-9)$ \\
\hline \multicolumn{7}{|c|}{$\begin{array}{l}\text { Note: Values are median with range in parentheses. Abbreviations as in Table } 1 . \\
\text { a } P<.05 \text { compared with medium-alone control. }\end{array}$} \\
\hline \multicolumn{7}{|c|}{ Hong. Cumulus oophorus and sperm penetration. Fertil Steril 2008.} \\
\hline
\end{tabular}




\section{FIGURE 2}

Effects of hyaluronic acid on spontaneous acrosome reaction $(n=10)$. Values are median and interquartile range. $P<.05$ compared with the medium-alone control.

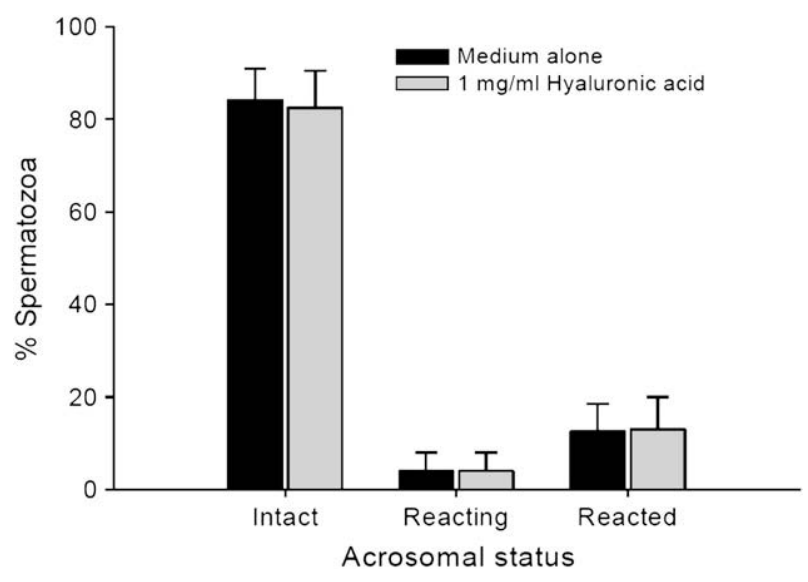

Hong. Cumulus oophorus and sperm penetration. Fertil Steril 2008.

sperm function (46). Superoxide anion is involved in the capacitation and hyperactivation of human spermatozoa (46, 47). Catalase prevents ionophore-induced acrosome reaction and oocyte fusion, whereas hydrogen peroxide stimulates these processes $(46,47)$. However, excessive ROS is detrimental to sperm functions (46) and is associated with male infertility $(46,48)$, suppressed sperm motility, ionophoreinduced acrosome reaction, and oocyte fusion. Thus, a fine balance between ROS production and scavenging is important for optimal sperm function (46-48).

Oxygen is directly involved in the generation of ROS. The presence of viable cumulus cells alters the oxygen tension inside the cumulus oophorus. There is no report on ROS concentration in the human cumulus oophorus due to its limited availability. In cows, cumulus-enclosed oocytes are better fertilized than cumulus-denuded oocytes, and the former generate more ROS (36). Viable cumulus cells protect porcine oocyte from oxidative stress-induced apoptotic damage (49). These data are consistent with the involvement of viable cumulus cells in maintaining an optimal ROS microenvironment for fertilization.

There are two other possibilities for the low penetrability of spermatozoa in the overnight matrix. The matrix may have been damaged during the freeze-thaw cycles. This possibility is unlikely, because the gross appearance and texture of the cell-depleted matrix was preserved after the freezing and thawing procedure, and the effects of cumulus oophorus on sperm penetration could also be observed in the fresh matrix. Another possibility is the presence of detrimental factor(s), e.g., proteases released during cell lysis, affecting the penetrability of the spermatozoa. The observation that the fresh matrix, which should have the highest concentration of these factor(s), had similar effect on the penetrability of spermatozoa as that of cumulus oophorus speaks against the likelihood of this possibility.

The effects of cumulus mass on sperm function in this study are consistent with our recent report (17); spermatozoa passing through the cumulus oophorus had higher percentages of spermatozoa with normal morphology and acrosome reaction and had specific motility pattern described as cumulus-related motility (50). Except for the reduction in penetrability of spermatozoa, fresh matrix had effects similar to that of the cumulus oophorus, suggesting that these effects do not require viable cumulus cells. The effects in the fresh matrix could be due to the presence of factors originating from lysis of the cumulus cells or from the follicular fluid that are trapped within matrix during cumulus expansion. These factors diffuse out of the matrix or become diluted after prolonged incubation. resulting in loss of the effects in the overnight matrix.

The present study is the first to investigate the effect of hyaluronic acid at a concentration $(1.0 \mathrm{mg} / \mathrm{mL})$ similar to that in the cumulus oophorus on sperm function; much lower concentrations had been used in earlier reports $(20,27)$. In the present study, hyaluronic acid did not affect acrosome reaction, but it modulated sperm motility. This is in line with the presence of receptors for hyaluronic acid in human spermatozoa $(20,51,52)$. Although hyaluronic acid does not affect spontaneous acrosome reaction, an earlier report (27) and our unpublished observation have shown that hyaluronic acid enhances progesterone-stimulated acrosome reaction. This latter effect of hyaluronic acid is mediated by $\mathrm{PH}-20$ protein through increasing the basal level of intracellular calcium of the treated spermatozoa (27). On the other hand, cumulus cell extract induced spontaneous acrosome reaction of spermatozoa. The molecule(s) in the cumulus extract affecting acrosome reaction is not known. A possible candidate is progesterone. Cumulus cells produce progesterone $(53,54)$, which is known to induce acrosome reaction (55).

Compared with spermatozoa in medium only, the motion of human spermatozoa in the cumulus matrix is characterized by moving more linearly with higher LIN and BCF and lower ALH (50). This cumulus-related motility of the spermatozoa could be beneficial to penetration through the mucoelastic cumulus matrix. Similar cumulus-related motility was found in spermatozoa that had penetrated the cumulus oophorus in the present study. A slight difference in the two studies is noted: The velocity of the spermatozoa is lower in the former but higher in the latter compared with the control spermatozoa in culture medium. This could be due to the fact that Tesarik et al. measured sperm motility in the cumulus oophorus, whereas we determined sperm motility in culture medium.

Hyaluronic acid may stimulate human sperm motility by increasing intracellular calcium concentration $(20,27)$. Evidence suggests that hyaluronic acid has differential effects on spermatozoa with different motile capacity. At a concentration of $200 \mathrm{ng} / \mathrm{mL}$, hyaluronic acid enhanced sperm 
motility in normospermic and oligospermic samples (56). However, the motility of swim-up-processed spermatozoa was enhanced only when the concentration of hyaluronic acid was higher $(650 \mathrm{ng} / \mathrm{mL})$, suggesting that low concentration of hyaluronic acid affected only the motility of a lessmotile sperm subpopulation (20). At a concentration similar to that in the cumulus oophorus, hyaluronic acid increased VAP, VSL, and LIN of treated spermatozoa, reproducing some of the effects of cumulus oophorus on sperm motility. However, it alone cannot explain the increase in BCF and decrease in ALH of the spermatozoa passing through the cumulus oophorus. Other factors are likely to be involved. In this regard, several partially purified fractions of cumulus matrix have been shown to induce cumulus-related motility (50).

The reason for the lack of effect of overnight matrix containing hyaluronic acid on sperm motility is unknown. Binding proteins for hyaluronic acid have been identified in human cumulus cells (57). Therefore, it is possible that the release of these binding proteins after lysis of the cumulus cells bind to hyaluronic acid in the matrix during overnight incubation, reducing the motility-stimulating action of the matrix by blocking the binding of hyaluronic acid to the penetrating spermatozoa.

In conclusion, both the cumulus matrix and the cumulus cells contribute to the effect of cumulus oophorus on spermatozoa penetrating through it. Cumulus cell viability is important in maintaining the penetrability to spermatozoa. Hyaluronic acid is one of the components in the matrix affecting sperm motility, although it alone cannot explain all of the cumulus matrix-induced changes in motility parameters. The identity of factor(s) in the cumulus cell extract responsible for inducing acrosome reaction needs further investigation.

Acknowledgments: The authors thank the laboratory staff and the assisted reproduction team for their skilful technical assistance.

\section{REFERENCES}

1. Pereda J, Coppo M. An electron microscopic study of sperm penetration into the human egg investments. Anat Embryol (Berl) 1985;173:247-52.

2. Cummins JM, Yanagimachi R. Development of ability to penetrate the cumulus oophorus by hamster spermatozoa capacitated in vitro, in relation to the timing of acrosome reaction. Gamete Res 1986;15:187-212.

3. Tsuiki A, Hoshiai H, Takahashi K, Suzuki M, Hoshi K. Sperm-egg interactions observed by scanning electron microscopy. Arch Androl 1986;16:35-47.

4. Dandekar P, Aggeler J, Talbot P. Structure, distribution and composition of the extracellular matrix of human oocytes and cumulus masses. Hum Reprod 1992;7:391-8.

5. Chen C, Sathananthan AH. Early penetration of human sperm through the vestments of human eggs in vitro. Arch Androl 1986;16:183-97.

6. Cherr GN, Lambert H, Meizel S, Katz DF. In vitro studies of the golden hamster sperm acrosome reaction: completion on the zona pellucida and induction by homologous soluble zonae pellucidae. Dev Biol 1986;114: 119-31.

7. Corselli J, Talbot P. In vitro penetration of hamster oocyte-cumulus complexes using physiological numbers of sperm. Dev Biol 1987;122: 227-42.

8. Hizaki H, Segi E, Sugimoto Y, Hirose M, Saji T, Ushikubi F, et al. Abortive expansion of the cumulus and impaired fertility in mice lacking the prostaglandin E receptor subtype EP(2). Proc Natl Acad Sci U S A 1999;96:10501-6.

9. Zhuo L, Yoneda M, Zhao M, Yingsung W, Yoshida N, Kitagawa Y, et al. Defect in SHAP-hyaluronan complex causes severe female infertility. A study by inactivation of the bikunin gene in mice. J Biol Chem 2001;276: 7693-6.

10. Fulop C, Szanto S, Mukhopadhyay D, Bardos T, Kamath RV, Rugg MS, et al. Impaired cumulus mucification and female sterility in tumor necrosis factor-induced protein-6 deficient mice. Development 2003;130: 2253-61.

11. Sullivan R, Duchesne C, Fahmy N, Morin N, Dionne P. Protein synthesis and acrosome reaction-inducing activity of human cumulus cells. Hum Reprod 1990;5:830-4.

12. Bastias MC, Kamijo H, Osteen KG. Assessment of human sperm functional changes after in-vitro coincubation with cells retrieved from the human female reproductive tract. Hum Reprod 1993;8:1670-7.

13. Fetterolf PM, Jurisicova A, Tyson JE, Casper RF. Conditioned medium from human cumulus oophorus cells stimulates human sperm velocity. Biol Reprod 1994;51:184-92.

14. Mansour RT, Aboulghar MA, Serour GI, Abbas AM, Elattar I. The life span of sperm motility and pattern in cumulus coculture. Fertil Steril 1995;63:660-2.

15. Hossain AM, Rizk B, Huff C, Helvacioglu A, Thorneycroft IH. Human sperm bioassay has potential in evaluating the quality of cumulus-oocyte complexes. Arch Androl 1996;37:7-10.

16. Yao Y, Ho P, Yeung WS. Effects of human follicular fluid on spermatozoa that have been cocultured with human oviductal cells. Fertil Steril 1999;72:1079-84.

17. Hong SJ, Chiu PC, Lee KF, Tse JMY, Ho PC, Yeung WSB. Establishment of a capillary-cumulus model to study the selection of sperm for fertilization by cumulus oophorus. Hum Reprod 2004;19:1562-9.

18. Chiu PC, Chung MK, Koistinen R, Koistinen H, Seppala M, Ho PC, et al. Cumulus oophorus-associated glycodelin-C displaces sperm-bound glycodelin-A and $-\mathrm{F}$ and stimulates spermatozoa-zona pellucida binding. J Biol Chem 2007;282:5378-88.

19. Hong SJ, Tse JY, Ho PC, Yeung WS. Cumulus cells reduce the spermatozoa-zona binding inhibitory activity of human follicular fluid. Fertil Steril 2003;79(Suppl 1):802-7.

20. Bains R, Miles DM, Carson RJ, Adeghe J. Hyaluronic acid increases motility/intracellular CA2+ concentration in human sperm in vitro. Arch Androl 2001;47:119-25.

21. Sun F, Bahat A, Gakamsky A, Girsh E, Katz N, Giojalas LC, et al. Human sperm chemotaxis: both the oocyte and its surrounding cumulus cells secrete sperm chemoattractants. Hum Reprod 2005;20:761-7.

22. Salustri A, Yanagishita M, Hascall VC. Synthesis and accumulation of hyaluronic acid and proteoglycans in the mouse cumulus cell-oocyte complex during follicle-stimulating hormone-induced mucification. J Biol Chem 1989;264:13840-7.

23. Talbot P. Hyaluronidase dissolves a component in the hamster zona pellucida. J Exp Zool 1984;229:309-16.

24. Camaioni A, Hascall VC, Yanagishita M, Salustri A. Effects of exogenous hyaluronic acid and serum on matrix organization and stability in the mouse cumulus cell-oocyte complex. J Biol Chem 1993;268:20473-81.

25. Chen L, Russell PT, Larsen WJ. Functional significance of cumulus expansion in the mouse: roles for the preovulatory synthesis of hyaluronic acid within the cumulus mass. Mol Reprod Dev 1993;34:87-93.

26. Zhuo L, Kimata K. Cumulus oophorus extracellular matrix: its construction and regulation. Cell Struct Funct 2001;26:189-96.

27. Sabeur K, Cherr GN, Yudin AI, Overstreet JW. Hyaluronic acid enhances induction of the acrosome reaction of human sperm through interaction with the PH-20 protein. Zygote 1998;6:103-11.

28. World Health Organization. Laboratory manual for the examination of human semen and semen-cervical mucus interaction. New York: Cambridge University Press, 1999.

29. Ng EH, Yeung WS, Yee LL, So WW, Ho PC. High serum oestradiol concentrations in fresh IVF cycles do not impair implantation and pregnancy rates in subsequent frozen-thawed embryo transfer cycles. Hum Reprod 2000;15:250-5. 
30. Ling JY, Kienzle TE, Stroop WG. An improved rapid method for purification of herpes simplex virus DNA using cesium trifluoroacetate. J Virol Methods 1996;58:193-8.

31. Huszar G, Celik-Ozenci C, Cayli S, Kovacs T, Vigue L, Kovanci E. Semen characteristics after overnight shipping: preservation of sperm concentrations, HspA2 ratios, CK activity, cytoplasmic retention, chromatin maturity, DNA integrity, and sperm shape. J Androl 2004;25:593-604.

32. Menkveld R, Stander FS, Kotze TJ, Kruger TF, van Zyl JA. The evaluation of morphological characteristics of human spermatozoa according to stricter criteria. Hum Reprod 1990;5:586-92.

33. Chiu PC, Chung MK, Tsang HY, Koistinen R, Koistinen H, Seppala M, et al. Glycodelin-S in human seminal plasma reduces cholesterol efflux and inhibits capacitation of spermatozoa. J Biol Chem 2005;280: 25580-9.

34. Chiu PC, Ho PC, Ng EH, Yeung WS. Comparative study of the biological activity of spermatozoa-zona pellucida binding inhibitory factors from human follicular fluid on various sperm function parameters. Mol Reprod Dev 2002;61:205-12.

35. Chiu PC, Koistinen R, Koistinen H, Seppala M, Lee KF, Yeung WS. Binding of zona binding inhibitory factor-1 (ZIF-1) from human follicular fluid on spermatozoa. J Biol Chem 2003;278:13570-7.

36. Tanghe S, Van Soom A, Nauwynck H, Coryn M, de Kruif A. Minireview: functions of the cumulus oophorus during oocyte maturation, ovulation, and fertilization. Mol Reprod Dev 2002;61:414-24.

37. Rodgers RJ, Irving-Rodgers HF, Russell DL. Extracellular matrix of the developing ovarian follicle. Reproduction 2003;126:415-24.

38. Suarez SS, Pacey AA. Sperm transport in the female reproductive tract. Hum Reprod Update 2006;12:23-37.

39. Jones AR. Metabolism of lactate by mature boar spermatozoa. Reprod Fertil Dev 1997;9:227-32.

40. O'Flaherty CM, Beorlegui NB, Beconi MT. Lactate dehydrogenase-C4 is involved in heparin- and NADH-dependent bovine sperm capacitation. Andrologia 2002;34:91-7.

41. Goldberg E. Molecular basis for multiple forms of LDH-X. J Exp Zool 1973;186:273-8.

42. Gerez dBN, Burgos C, Coronel CE, Bertarelli DC, Pigini T, Blanco A. Correlation of lactate dehydrogenase isoenzyme $\mathrm{C} 4$ activity with the count and motility of human spermatozoa. J Reprod Fertil 1979;55:107-11.

43. Gavella M, Cvitkovic P. Semen LDH-X deficiency and male infertility. Arch Androl 1985;15:173-6.

44. Gardner DK, Lane M, Calderon I, Leeton J. Environment of the preimplantation human embryo in vivo: metabolite analysis of oviduct and uterine fluids and metabolism of cumulus cells. Fertil Steril 1996;65: 349-53.

45. Gardner DK, Leese HJ. Concentrations of nutrients in mouse oviduct fluid and their effects on embryo development and metabolism in vitro. J Reprod Fertil 1990;88:361-8.

46. Baker MA, Aitken RJ. The importance of redox regulated pathways in sperm cell biology. Mol Cell Endocrinol 2004;216:47-54.

47. de Lamirande E, Jiang H, Zini A, Kodama H, Gagnon C. Reactive oxygen species and sperm physiology. Rev Reprod 1997;2:48-54.

48. Baker MA, Aitken RJ. Reactive oxygen species in spermatozoa: methods for monitoring and significance for the origins of genetic disease and infertility. Reprod Biol Endocrinol 2005;29:67.

49. Tatemoto H, Sakurai N, Muto N. Protection of porcine oocytes against apoptotic cell death caused by oxidative stress during In vitro maturation: role of cumulus cells. Biol Reprod 2000;63:805-10.

50. Tesarik J, Mendoza OC, Testart J. Effect of the human cumulus oophorus on movement characteristics of human capacitated spermatozoa. J Reprod Fertil 1990;88:665-75.

51. Kornovski BS, McCoshen J, Kredentser J, Turley E. The regulation of sperm motility by a novel hyaluronan receptor. Fertil Steril 1994;61: 935-40.

52. Ranganathan S, Ganguly AK, Datta K. Evidence for presence of hyaluronan binding protein on spermatozoa and its possible involvement in sperm function. Mol Reprod Dev 1994;38:69-76.

53. Dirnfeld M, Goldman S, Gonen Y, Koifman M, Lissak A, Kraiem Z, et al. Functional differentiation in progesterone secretion by granulosa versus cumulus cells in the human preovulatory follicle and the effect of different induction of ovulation protocols. Fertil Steril 1993;60:1025-30.

54. Chian RC, Ao A, Clarke HJ, Tulandi T, Tan SL. Production of steroids from human cumulus cells treated with different concentrations of gonadotropins during culture in vitro. Fertil Steril 1999;71:61-6.

55. Luconi M, Francavilla F, Porazzi I, Macerola B, Forti G, Baldi E. Human spermatozoa as a model for studying membrane receptors mediating rapid nongenomic effects of progesterone and estrogens. Steroids 2004;69:553-9.

56. Huszar G, Willetts M, Corrales M. Hyaluronic acid (Sperm Select) improves retention of sperm motility and velocity in normospermic and oligospermic specimens. Fertil Steril 1990;54:1127-34.

57. Ohta N, Saito H, Kuzumaki T, Takahashi T, Ito MM, Saito T, et al. Expression of CD44 in human cumulus and mural granulosa cells of individual patients in in-vitro fertilization programmes. Mol Hum Reprod 1999;5:22-8. 